Nebojša Ralević

Nataša Glišović ${ }^{2}$

Vladimir Đaković ${ }^{3}$

Goran Anđelić ${ }^{4}$
JEL:C45, C53, G17

DOI:10.5937/industrija45-11052

UDC:339.13

005.52:005.334]:004.032.26

005.521

Original Scientific Paper

\title{
Hybrid System Prediction for the Stock Market: The Case of Transitional Markets ${ }^{5}$
}

\author{
Article history: \\ Received: 2 June 2016 \\ Sent for revision:6 June 2016 \\ Received in revised form: 20 January 2017 \\ Accepted: 21 January 2017 \\ Available online: 5 April 2017
}

\begin{abstract}
The subject of this paper is the creation and testing of an enhanced fuzzy neural network backpropagation model for the prediction of stock market indexes, including the comparison with the traditional neural network backpropagation model. The objective of the research is to gather information concerning the possibilities of using the enhanced fuzzy neural network backpropagation model for the prediction of stock market indexes focusing on transitional markets. The methodology used involves the integration of fuzzified weights into the neural network. The research results will be beneficial both for the broader investment community and the academia, in terms of the application of the enhanced model in the investment decisionmaking, as well as in improving the knowledge in this subject matter.
\end{abstract}

Keywords: Hybrid System, Neural Networks, Prediction, Stock, Market, Investments.

\section{Prediktivni hibridni sistem za berzansko tržište: Slučaj tranzitornih tržišta}

Apstrakt: Predmet istraživanja u radu jeste kreiranje i testiranje poboljšanog fuzzy neural network backpropagation modela za predikciju berzanskih

\footnotetext{
${ }^{1}$ University of Novi Sad, Faculty of Technical Sciences, Serbia

2 State University of Novi Pazar, Department of Mathematical Sciences, Serbia

${ }^{3}$ University of Novi Sad, Faculty of Technical Sciences, Serbia, v djakovic@uns.ac.rs

4 Educons University, Faculty of Business Economy, Serbia

5 This work was supported by the Ministry of Education, Science and Technological Development of the Republic of Serbia, within the Projects No. ON174009, No. III44006, and No. III47028.
} 
Ralević N. et al.: Hybrid System Prediction for the Stock Market: The Case of...

indeksa, uz poređenje sa tradicionalnim neural network backpropagation modelom. Cilj istraživanja jeste dolaženje do konkretnih saznanja o mogućnostima primene poboljšanog fuzzy neural network backpropagation modela za predikciju berzanskih indeksa, sa posebnim fokusom na tranzitorna tržišta. Metodologija korišćena u radu obuhvata integraciju fuzzyfikovanih tezina u neuro mreži. Rezultati istraživanja biće korisni kako široj investicionoj javnosti, tako $i$ akademskoj struci, u smislu korišćenja poboljšanog modela $u$ donošenju odluka o investiranju i unapređenju znanja $u$ predmetnoj oblasti.

Ključne reči: hibridni sistem, neuralne mreže, predikcija, akcija, tržište, investiranje.

\section{Introduction}

This paper proposes adjustment of weights in backpropagation model for neural networks by implementing fuzzy logic. The proposed approach differs from those that use adaptation (Beale, 1972; Fletcher \& Reeves, 1964; Moller, 1993; Powell, 1977), and/or fuzzy triangular or trapezoidal weights values (Ishibuchi, Morioka \& Tanaka, 1994; Ishibuchi, Tanaka \& Okada, 1993). Stock markets in transition economies are highly volatile, in particular given the consequences of the global economic crises. Due to the frequent occurrence of crisis situations, it is necessary to use advanced models for the optimal investment decision-making. Namely, portfolio investment return prediction in extremely dynamic business environment represents a substantial challenge considering the given conditions. In contrast to developed markets, transitional markets are particularly sensitive to frequent fluctuations in the investment processes because of their characteristics (shallow, low liquidity markets, etc.). Hence, in terms of creating the enhanced investment return prediction model they should be given special attention. In this regard, this paper discusses the modification of the existing fuzzy neural network backpropagation model for the prediction of stock market indexes in order to obtain the minimal error for stock market indexes time series. The results obtained by the enhanced model application are compared to the results obtained using the traditional neural network backpropagation model.

The paper is organized as follows. The first section gives introductory considerations; the second provides an overview of the relevant theoretical background. The research methodology is presented in the third section, followed by the results and discussion in the fourth section and then the findings are introduced and the review of the used literature. 
Ralević N. et al.: Hybrid System Prediction for the Stock Market: The Case of...

\section{Literature Review}

The most useful basic training method in the area of neural networks is the backpropagation model and its variations (Martinez, Melin, Bravo, Gonzalez \& Gonzalez, 2006; Cazorla \& Escolano, 2003; Hagan, Demuth \& Beale 1996; Phansalkar \& Sastry, 1994). When these methods are applied in practical problems, the training time of the basic backpropagation model can be very high (Moller, 1993; Salazar, Melin \& Castillo, 2008). In the literature several methods have been proposed to accelerate the convergence of the backpropagation model (Beale, 1972; Moller, 1993; Powell, 1997; Fletcher et al. 1964). There exists many works about adjustment or managing of weights, but only the most important and relevant for this paper will be considered here (Casasent \& Natarajan, 1995; Yam \& Chow, 2000; De Wilde, 1997; Draghici, 2002).

Gedeon (1999), using a discrete selection (following the Hebbian paradigm) performs the weight adjustment. Islam \& Murase (2001), as a strategy used the same weights in epochs where the output does not change. Meltser, Shoham \& Manevitz (1996), performed a weight adjustment of the network through the BFGS Quasi-Newton method (Broyden-Fletcher-GoldfarnShanno).

Barbounis and Theocharis (2007), performed the weights updating using the identification of recursive error prediction (RPE). Yeung, Chan \& $\mathrm{Ng}$ (2009), used a new training objective function to adjust the weights for a network with radial basis functions.

Kamarthi and Pittner (1999) used extrapolation for obtaining a weight prediction of the network at a future epoch. Neville and Eldridge (2002), worked with sigma-pi networks, which are transformed for performing a second task of assignation for which they were initially trained. Casasent et al. (1995) used weights with complex values and the nonlinear square law. Yam et al. (2000) developed an algorithm to find the initial optimal weights of feedforward neural networks based on the Cauchy inequality and a linear algebraic method. Draghici (2002), calculates a range of weights for a category of given problems and ensures that the network has the capacity to solve the given problems with integer weights in that range.

Ishibuchi et al. (1993, 1994), proposed a fuzzy network where the weights are given as trapezoidal fuzzy numbers or triangular fuzzy numbers. Feuring (1996) developed a learning algorithm in which the backpropagation model is used to compute the new lower and upper limits of weights. 
Ralević N. et al.: Hybrid System Prediction for the Stock Market: The Case of...

\section{Research Methodology}

The methodology used in this paper represents an integration of the traditional neural network backpropagation model and fuzzy data model, which are elaborated below.

\subsection{Traditional Neural Network Backpropagation Model}

The artificial neural networks are a collection of mathematical models which simulate some of the observed characteristics of biological neural systems and indicate similarities with adaptive biological learning. They are composed of a large number of interconnected neurons (processing elements) which are, similarly to biological neurons, making connections that contain weight coefficients whose function resembles synapses (Lin \& Lee, 1996).

The majority of neural networks have a certain set of rules for "training" used for adaption of neuron connections coefficients based on the input data. In other words, neural networks "learn" through examples and possess the capacity for generalization after the training.

The substantial potential of neural networks lies in the ability of parallel data processing during calculation of components that are independent of each other.

Neural networks are systems composed of a number of simple elements (neurons) engaged in parallel data processing. The network structure and interconnection strength determine functions that neural networks are able to process, whereas neurons are responsible for data processing. Each element operates only with local information and functions asynchronously.

BP neural network relies on a gradient algorithm to obtain the weights of the model and uses backpropagation model to minimize the objective function. BPNN typically consists of three layers: an input layer, a hidden layer and an output layer (Cheng \& Liu, 2014):

$$
\begin{gathered}
b_{j}=T\left(\sum_{i} r_{j i} a_{i}+\delta_{j}\right) \\
y_{i}=f\left(\sum_{i} w_{j i} x_{i}+\theta_{j}\right)
\end{gathered}
$$


Ralević N. et al.: Hybrid System Prediction for the Stock Market: The Case of...

$$
\begin{gathered}
z_{l}=g\left(\sum_{j} v_{l j} y_{i}+\phi_{l}\right) \\
E=\frac{1}{2} \sum_{l}\left(t_{l}-z_{l}\right)^{2}
\end{gathered}
$$

Where $b_{j}$ is the activation level of neuron $j . T$ is the transfer function, $r_{j i}$ is weight value, $\delta_{j}$ is bias. So the output of hidden layer and output layer described by the following equation (2) and (3). The error of output neuron is given by Equation (4). Where $x_{i}$ and $z_{l}$ are the input and output signals. $y_{i}$ is the output of the hidden layer. $w_{j i}$ is the weight between input neuron $j$ to hidden neuron $i . v_{l j}$ is the weight between hidden neuron $l$ to output neuron $j$. $\theta_{j}$ and $\phi_{l}$ are the biases for the hidden layer and output layer. $f$ and $g$ are transfer functions for hidden and output layers. $t_{l}$ is the expected output. $E$ is the error between the expected output and calculated output. In backpropagation models resilient BP was used (for details see (Riedmiller \& Braun, 1993)).

If the target values are positive, but the lack upper limit, it is best to use the exponential activation function. Since this is the case with the data used in the research, the exponential activation function has been selected.

\subsection{Fuzzification}

Fuzzification of weights in hidden layers is performed according to the minimum and maximum values of a stock market index on daily basis. The weight limits obtained this way (see model step 2.) are inserted in neural network. The research findings have proven that in this way the prediction is enhanced.

The architecture of the fuzzy neural network can be described as follows:

Step 1. Inputs $X=\left[x_{1}, x_{2}, \ldots, x_{n}\right]$

Step 2. Determining interval fuzzy weights in hidden layer $\widetilde{w} \in[\underline{w}, \bar{w}]$

$$
\bar{w}=\frac{\sum_{k=1}^{N} \bar{f}^{k} w_{1}^{k}}{\sum_{k=1}^{N} \bar{f}^{k}}
$$


Ralević N. et al.: Hybrid System Prediction for the Stock Market: The Case of...

$$
\underline{w}=\frac{\sum_{k=1}^{N} \underline{f}^{k} w_{1}^{k}}{\sum_{k=1}^{N} \underline{f}^{k}}
$$

Where $\mathrm{N}$ is an input length, where $f$ and $\bar{f}$ are the minimal and maximal index value at that date.

Step 3. Hidden neurons with fuzzy interval weights Net $=\sum_{i=1}^{n} x_{i} \widetilde{w}_{i}$.

Step 4. Output neurons with fuzzy interval weights Out $=\sum_{i=1}^{n} y_{i} \widetilde{w}_{i}$.

Step 5. Obtain a single output of the neural network.

\section{Results and Discussion}

The proposed model is implemented in the programme language C\#. Its success of prediction has been tested on the stock market indexes BELEX15, CROBEX, SBITOP and BUX. The learning period of the hybrid model was from $4^{\text {th }}$ October, 2005 to $30^{\text {th }}$ November, 2014. The prediction was performed the following month (December 1-31) (Fig. 1, Fig. 2, Fig. 3, Fig. 4) and December-January (Fig. 5, Fig. 6, Fig. 7 and Fig. 8) and December-February (Fig. 9, Fig. 10, Fig. 11 and Fig. 12).

Figure 1. The review comparison - traditional and fuzzy NNBP of the prediction results for the period from $1^{\text {st }}-31^{\text {st }}$ December for stock market index BELEX 15

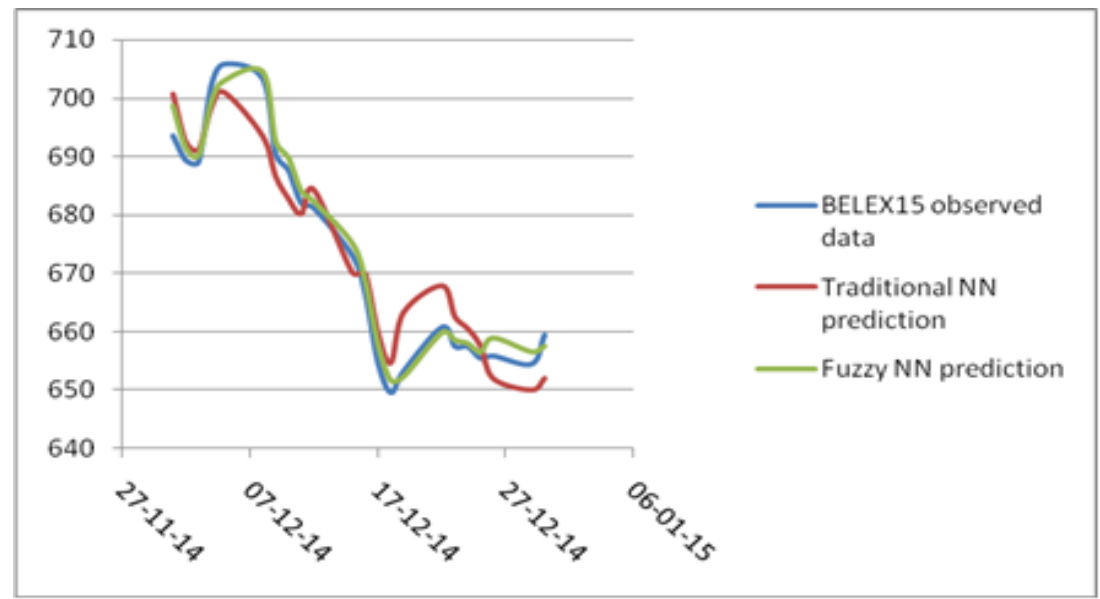

Source: the authors' calculations 
Ralević N. et al.: Hybrid System Prediction for the Stock Market: The Case of...

Figure 2. The review comparison - traditional and fuzzy NNBP of the prediction results for the period from 1st-31st December for stock market index CROBEX

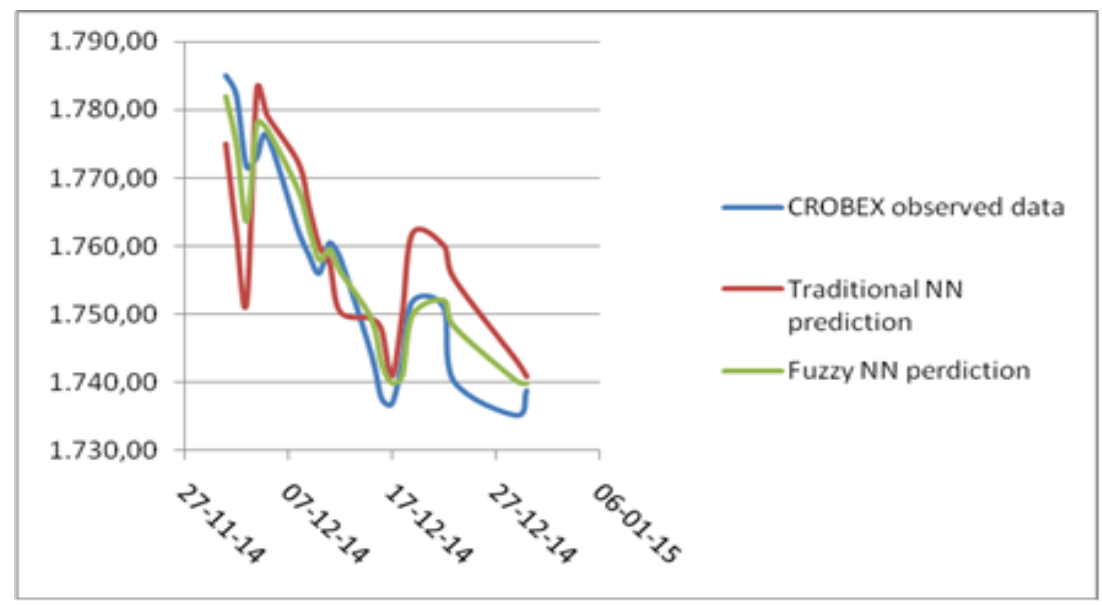

Source: the authors' calculations

Figure 3. The review comparison - traditional and fuzzy NNBP of the prediction results for the period from 1st-31st December for stock market index SBITOP

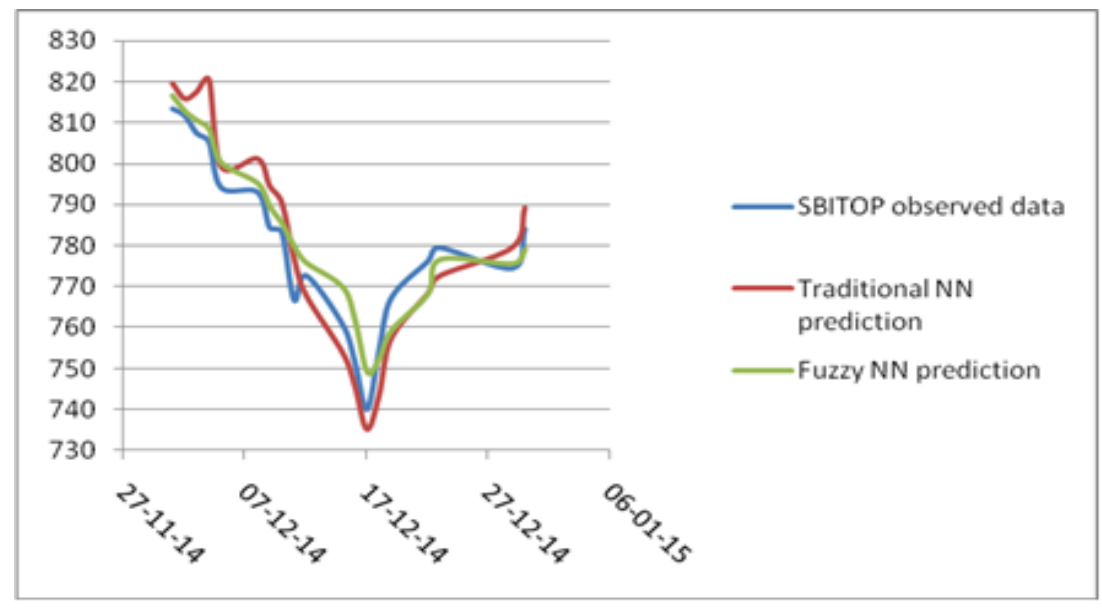

Source: the authors' calculations 
Ralević N. et al.: Hybrid System Prediction for the Stock Market: The Case of...

Figure 4. The review comparison - traditional and fuzzy NNBP of the prediction results for the period from 1st-31st December for stock market index $B U X$

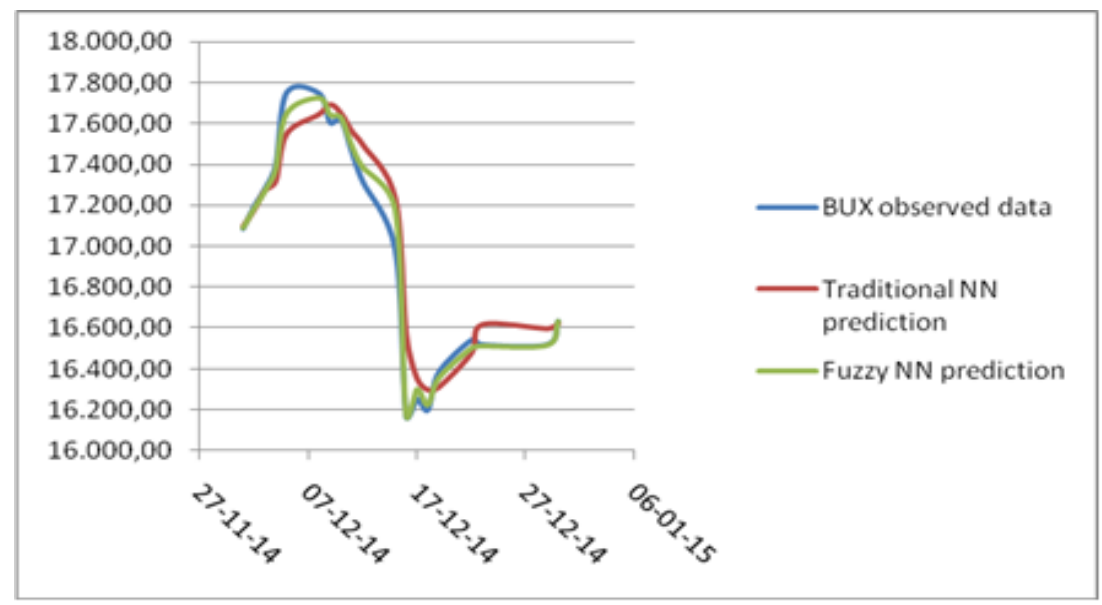

Source: the authors' calculations

Figure 5. The review comparison - traditional and fuzzy NNBP of the prediction results for the period from December to January for stock market index SBITOP

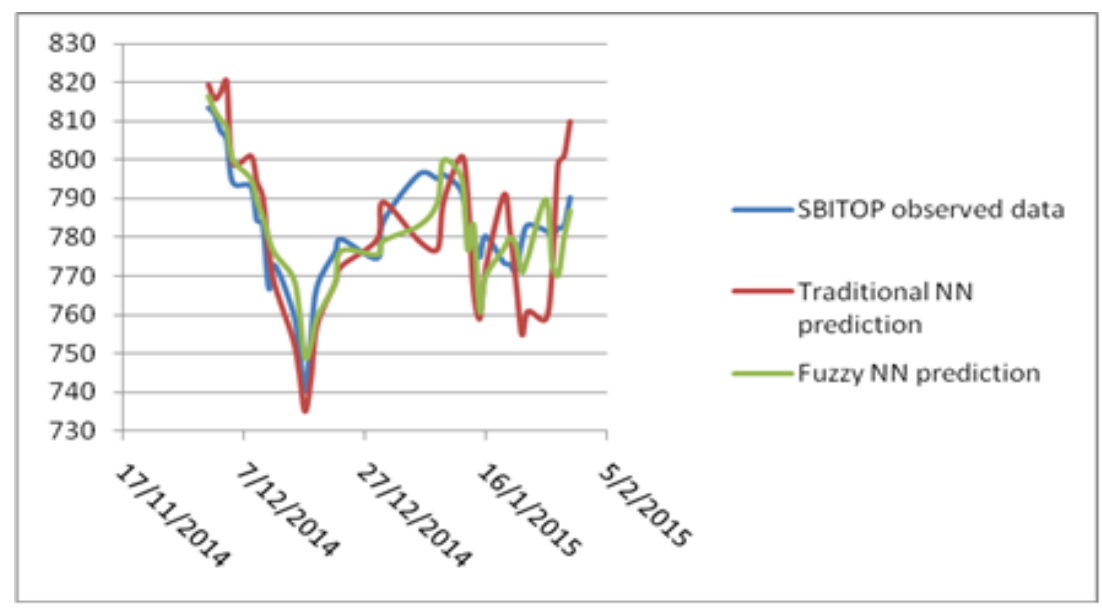

Source: the authors' calculations 
Ralević N. et al.: Hybrid System Prediction for the Stock Market: The Case of...

Figure 6. The review comparison - traditional and fuzzy NNBP of the prediction results for the period from December to January for stock market index $B U X$

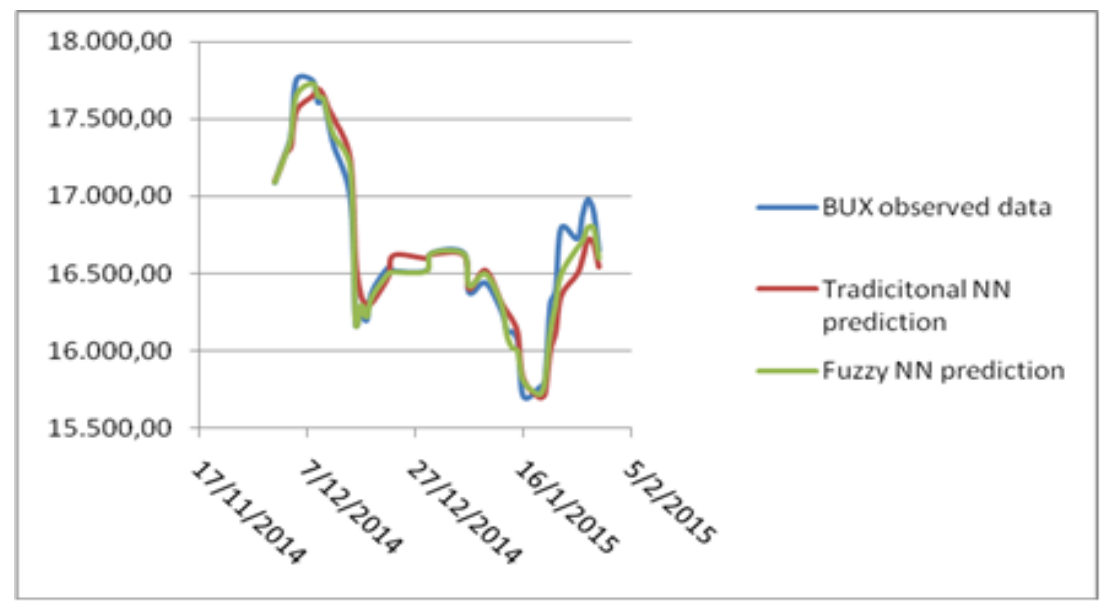

Source: the authors' calculations

Figure 7. The review comparison - traditional and fuzzy NNBP of the prediction results for the period from December to January for stock market index BELEX15

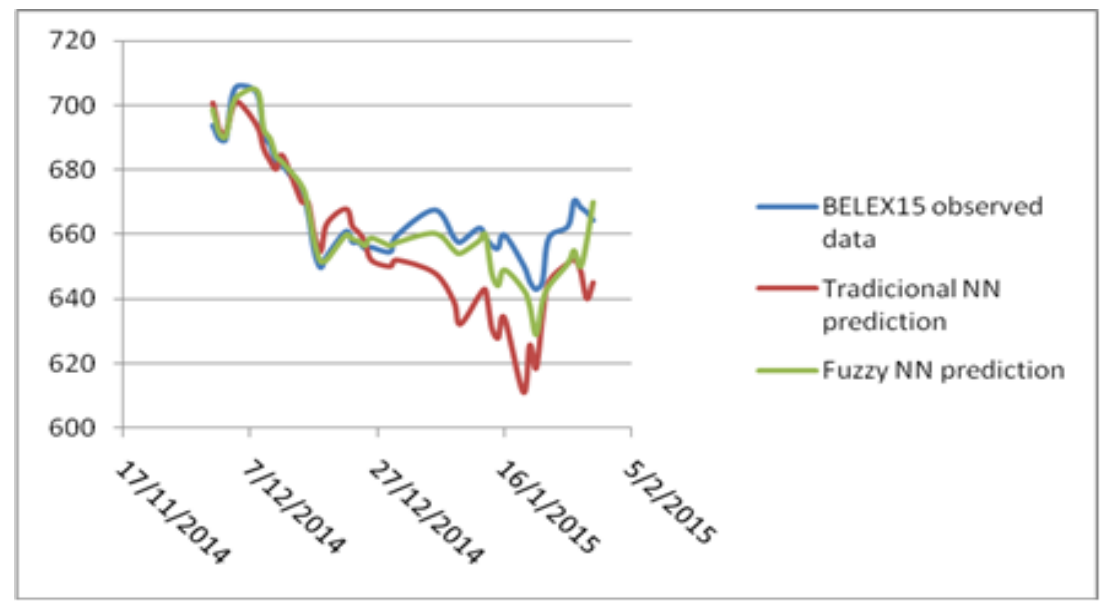

Source: the authors' calculations 
Ralević N. et al.: Hybrid System Prediction for the Stock Market: The Case of...

Figure 8. The review comparison - traditional and fuzzy NNBP of the prediction results for the period from December to January for stock market index CROBEX

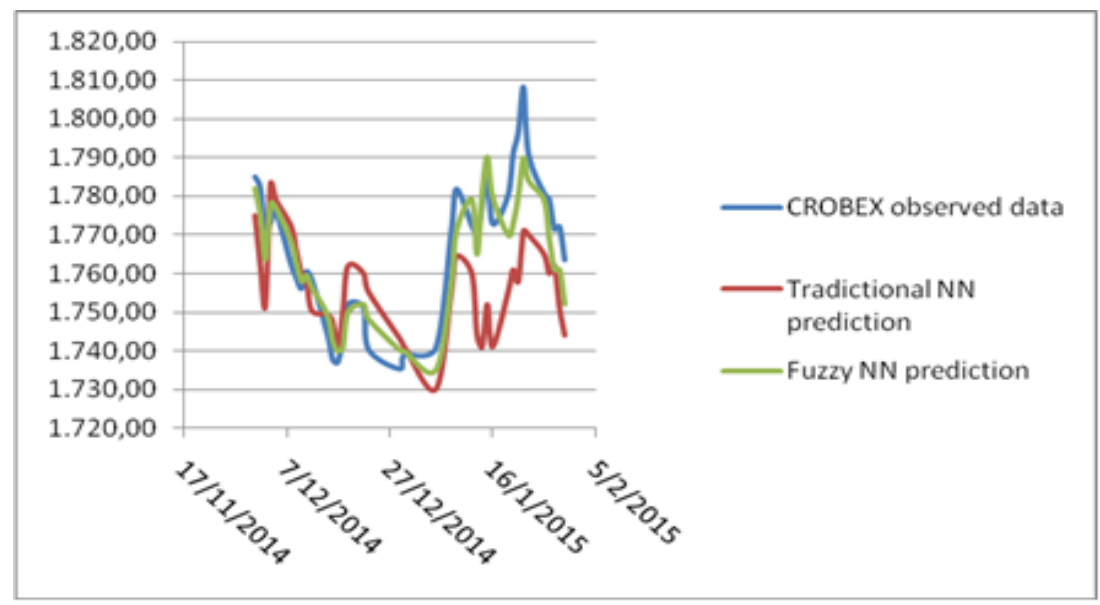

Source: the authors' calculations

Figure 9. The review comparison - traditional and fuzzy NNBP of the prediction results for the period from December to February for stock market index SBITOP

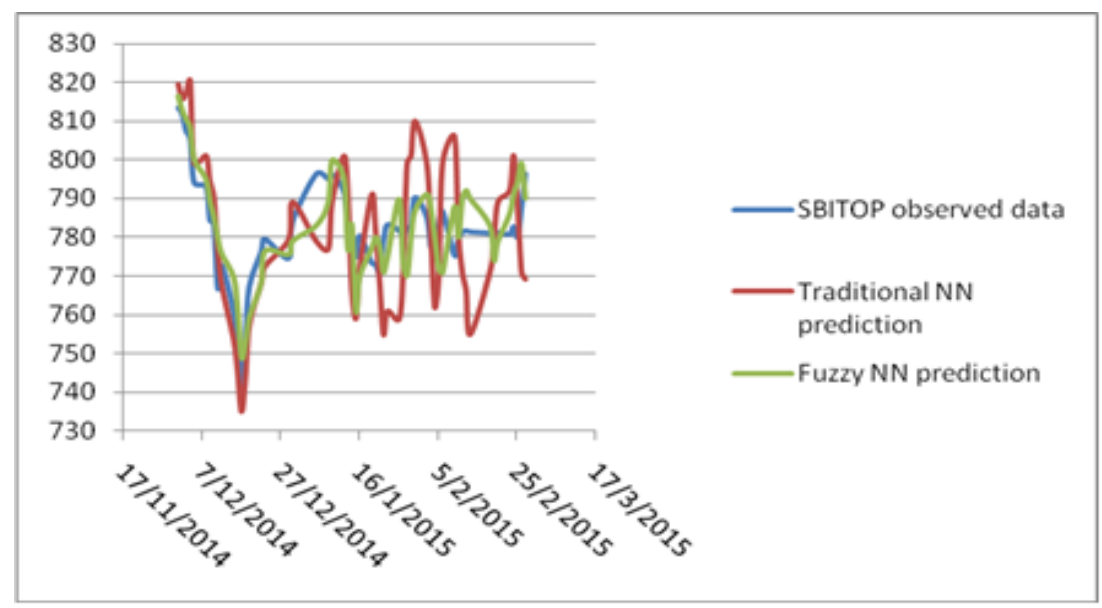

Source: the authors' calculations 
Ralević N. et al.: Hybrid System Prediction for the Stock Market: The Case of...

Figure 10. The review comparison - traditional and fuzzy NNBP of the prediction results for the period from December to February for stock market index BELEX15

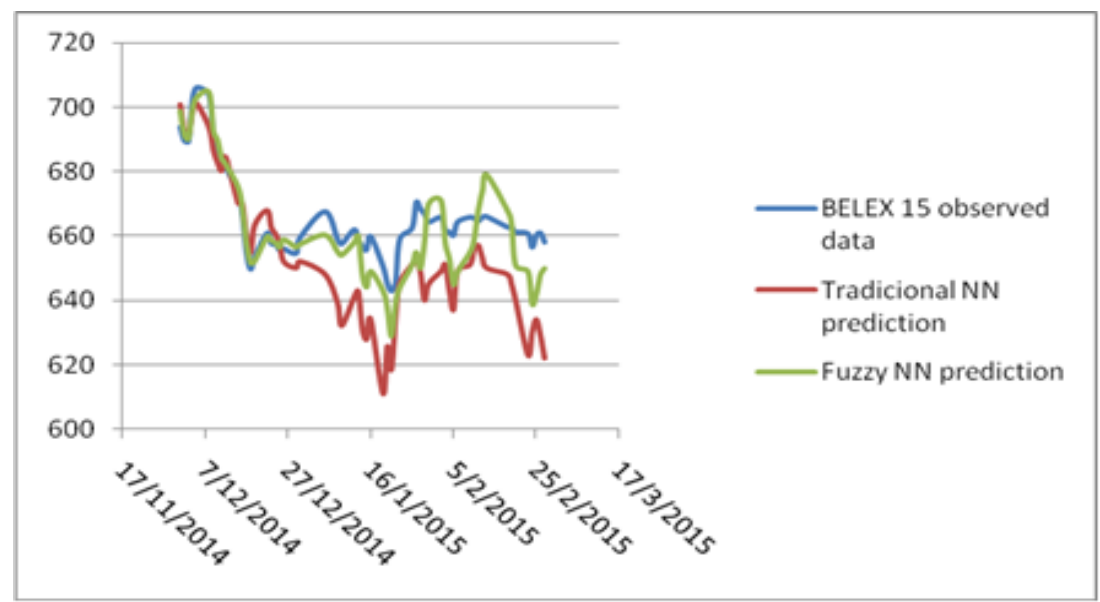

Source: the authors' calculations

Figure 11. The review comparison - traditional and fuzzy NNBP of the prediction results for the period from December to February for stock market index $B U X$

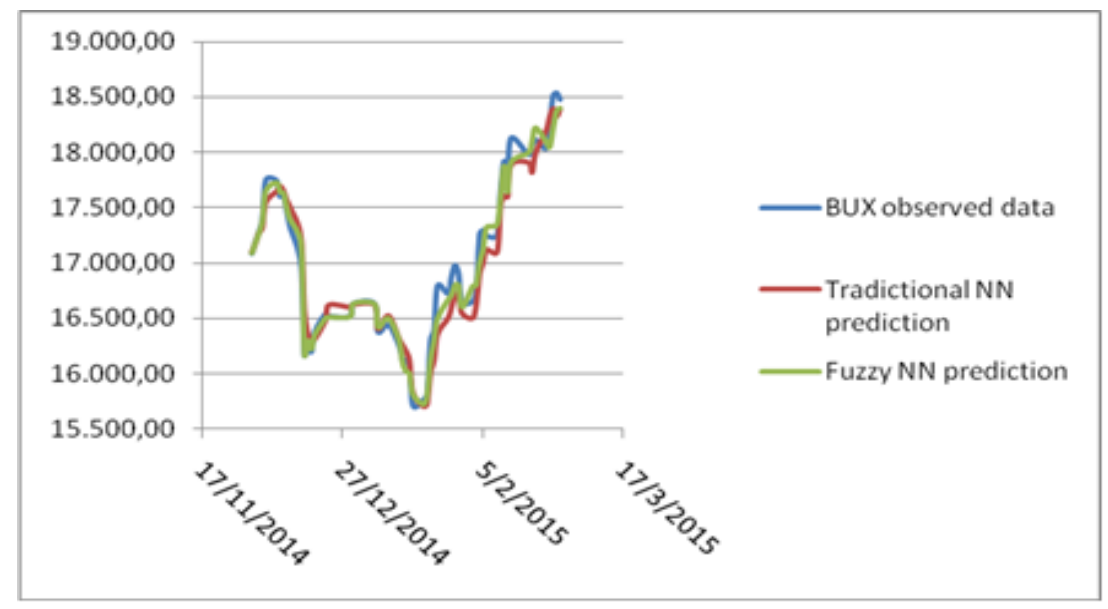

Source: the authors' calculations 
Ralević N. et al.: Hybrid System Prediction for the Stock Market: The Case of...

Figure 12. The review comparison - traditional and fuzzy NNBP of the prediction results for the period from December to February for stock market index CROBEX

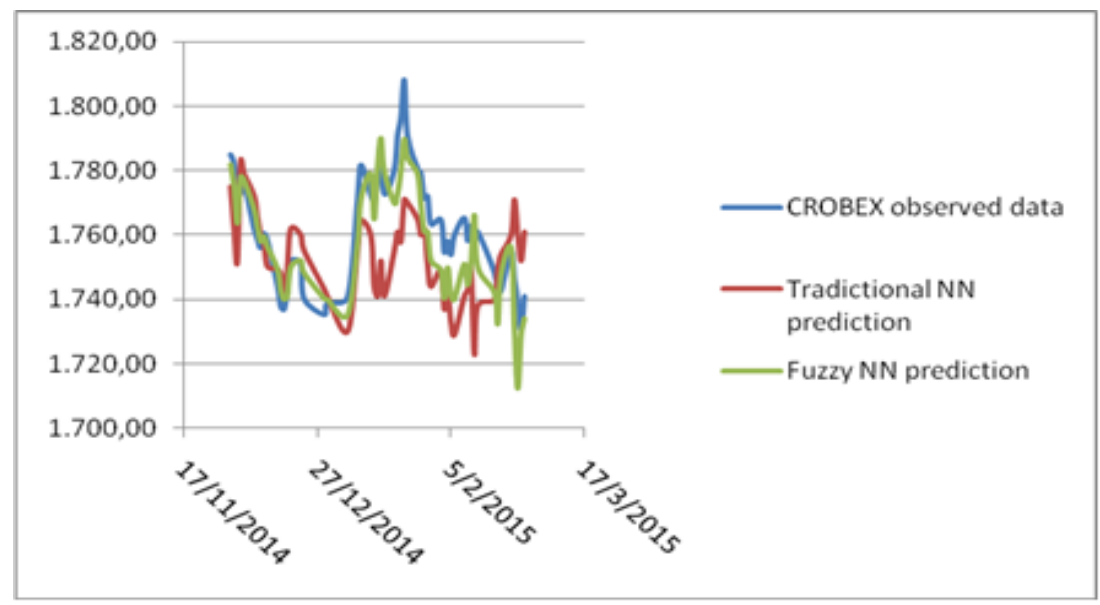

Source: the authors' calculations

After fitting time series model, it can be evaluated with forecast fit measures. The forecast value can be subtracted from the observed value of the data at that time point and obtain a measure of error. To evaluate the amount of this forecast error, the mean error or the mean absolute error may be employed (the mean absolute error (MAE) and the mean squared error (MSE)).

Performance models are compared through all errors and results shown in Table 1-Table 3.

Table 1. Performance models (hybrid and traditional) compared through MAE and MSE

\begin{tabular}{|l|c|c|}
\hline \multicolumn{1}{|c|}{ Prediction } & MAE & MSE \\
\hline Traditional BPNN for BELEX 15 & 4.74 & 27.58 \\
\hline Hybrid model for BELEX 15 & 1.93 & 4.74 \\
\hline Traditional BPNN for CROBEX & 8.68 & 100.58 \\
\hline Hybrid model for CROBEX & 3.74 & 18.84 \\
\hline Traditional BPNN for SBITOP & 7.58 & 64.95 \\
\hline Hybrid model for SBITOP & 5.05 & 37.05 \\
\hline Traditional BPNN for BUX & 104.37 & $19,758.79$ \\
\hline Hybrid model for BUX & 35.11 & $3,306.89$ \\
\hline
\end{tabular}

Source: the authors' calculations 
Ralević N. et al.: Hybrid System Prediction for the Stock Market: The Case of...

Table 2. Performance models (hybrid and traditional) compared through MAE and MSE (period from December-January)

\begin{tabular}{|l|c|c|}
\hline \multicolumn{1}{|c|}{ Prediction } & MAE & MSE \\
\hline Traditional BPNN for BELEX 15 & 12.22 & 239.70 \\
\hline Hybrid model for BELEX 15 & 5.03 & 47.05 \\
\hline Traditional BPNN for CROBEX & 15,89 & 362,66 \\
\hline Hybrid model for CROBEX & 6,49 & 64,21 \\
\hline Traditional BPNN for SBITOP & 10.92 & 152.35 \\
\hline Hybrid model for SBITOP & 6.01 & 48.74 \\
\hline Traditional BPNN for BUX & 128.65 & $28,154.42$ \\
\hline Hybrid model for BUX & 62.1 & $8,231.38$ \\
\hline
\end{tabular}

Source: the authors' calculations

Table 3. Performance models (hybrid and traditional) compared through MAE and MSE (period from December-February)

\begin{tabular}{|l|c|c|}
\hline \multicolumn{1}{|c|}{ Prediction } & MAE & MSE \\
\hline Traditional BPNN for BELEX 15 & 14.56 & 309.38 \\
\hline Hybrid model for BELEX 15 & 6.47 & 68.77 \\
\hline Traditional BPNN for CROBEX & 16.71 & 374 \\
\hline Hybrid model for CROBEX & 8.06 & 97.67 \\
\hline Traditional BPNN for SBITOP & 11.76 & 183.36 \\
\hline Hybrid model for SBITOP & 6.64 & 58.96 \\
\hline Traditional BPNN for BUX & 143.28 & $31,063.39$ \\
\hline Hybrid model for BUX & 81.42 & $12,380.99$ \\
\hline
\end{tabular}

Source: the authors' calculations

The research results suggest, based on the models performances through MAE and MSE (Tables 1-3), that enhanced hybrid model produces more optimal results than the traditional NN model for the tested sample. In the research, the comparison of the accuracy of the model prediction, when the prediction period is increased, (Fig. 5-12 and tables 2 and 3) was performed, and the results indicate that the increasment of the prediction period leads to the error increasment if the neural network training period remains unchanged.

NN model, as well as Fuzzy-NN model, learned until 01.12.2014. What followed was the error evaluation in the case of the increasment of the prediction period for the trained network (for one, two or three months). The model assessment indicates that the enhanced model outperforms the traditional one. Errors increase as the prediction period becomes longer. In each of the prediction scenarios the proposed model has outperformed the traditional model. 
Ralević N. et al.: Hybrid System Prediction for the Stock Market: The Case of...

\section{Conclusions}

The results obtained in this paper fully achieve the objective of this research obtaining the specific information regarding the possibility of applying the fuzzy neural network backpropagation model for the prediction of stock market indexes, with a particular focus on transitional markets of Serbia, Croatia, Slovenia and Hungary. The enhancement of existing model represents a significant step towards further development of modern methods of analysing the investment activities effects in dynamic and propulsive market conditions, with a particular focus on the four tested transitional markets.

In this regard, the research results have demonstrated that the enhanced hybrid type model provides the realistic basis for the further development of methods and techniques for analysis which will enable further advancements of investment activities towards a more successful prediction of the expected effects.

Further research directions will involve further testing and optimization of enhanced model proposed in the paper in order to create realistic assumptions for even more successful predictions of the effects of investment activities.

\section{References}

Casasent, D., \& Natarajan, S. (1995). A classifier neural net with complex-valued weights and square-law nonlinearities. Neural Networks, 8(6), 989-998.

Cazorla, M., \& Escolano, F. (2003). Two bayesian methods for junction classification, Image Processing. IEEE Transactions, 12(3), 317-327.

Cheng, L., \& Liu, J. (2014). An Optimized Neural Network Classifier for Automatic Modulator Recognition. TELKOMNIKA Indonesian Journal of Electrical Engineering, 12(2), 1343-1352.

Barbounis, T. G., \& Theocharis, J. B. (2007). Locally recurrent neural networks for wind speed prediction using spatial correlation. Information Sciences, 177(24), 5775-5797.

Beale, E. M. L. (1972). A derivation of conjugate gradients, in: F.A. Lootsma (Ed.), Numerical Methods for Nonlinear Optimization, Academic Press, London, 39-43.

De Wilde, O. (1997). The magnitude of the diagonal elements in neural networks. Neural Networks, 10(3), 499-504.

Draghici, S. (2002). On the capabilities of neural networks using limited precision weights. Neural Networks, 15(3), 395-414.

Feuring, T. (1996). Learning in fuzzy neural networks. IEEE International Conference, Neural Networks, 2, 1061-1066.

Fletcher, R., \& Reeves, C. M. (1964). Function minimization by conjugate gradients. The Computer Journal, 7, 149-154. 
Ralević N. et al.: Hybrid System Prediction for the Stock Market: The Case of...

Gedeon, T. (1999). Additive neural networks and periodic patterns. Neural Networks, 12(4-5), 617-626.

Hagan, M. T., Demuth, H. B., \& Beale, M. H. (1996). Neural Network Design. PWS Publishing, Boston.

Ishibuchi, H., Tanaka, H., \& Okada, H. (1993). Fuzzy neural networks with fuzzy weights and fuzzy biases. IEEE International Conference, Neural Networks 3, 1650-1655.

Ishibuchi, H., Morioka, K., \& Tanaka, H. (1994). A fuzzy neural network with trapezoid fuzzy weights. Fuzzy Systems, IEEE World Congress on Computational Intelligence, 1, 228-233.

Islam, Md. M., \& Murase, K. (2001). A new algorithm to design compact two-hiddenlayer artificial neural networks. Neural Networks, 14(9), 1265-1278.

Kamarthi, S., \& Pittner, S. (1999). Accelerating neural network training using weight extrapolations. Neural Networks, 12(9), 1285-1299.

Lin, C. T., \& Lee, C. S. G. (1996). Neural Fuzzy Systems. Prentice Hall.

Martinez, G., Melin, P., Bravo, D., Gonzalez, F., \& Gonzalez, M. (2006). Modular neural networks and fuzzy sugeno integral for face and fingerprint recognition. Applied Soft Computing Technologies, 34, 603-618.

Meltser, M., Shoham, M., \& Manevitz, L. (1996). Approximating functions by neural networks: a constructive solution in the uniform norm. Neural Networks, 9(6), 965-978.

Moller, M. F. (1993). A scaled conjugate gradient algorithm for fast supervised learning. Neural Networks, 6(4), 525-533.

Neville, R. S., \& Eldridge, S. (2002). Transformations of sigma-Pi nets: obtaining reflected functions by reflecting weight matrices. Neural Networks, 15(3), 375393.

Phansalkar, V. V., \& Sastry, P. S. (1994). Analysis of the back-propagation algorithm with momentum. IEEE Transactions on Neural Networks, 5(3), 505-506.

Powell, M. J. D. (1977). Restart procedures for the conjugate gradient method. Mathematical Programming, 12(1), 241-254.

Riedmiller, M., \& Braun, H. (1993). A Direct Adaptive Method for Faster Backpropagation Learning: The RPROP Algorithm, In: Ruspini, H., (Ed.) Proceedings of the ICNN 93, San Francisco, 586-591.

Salazar, P. A., Melin, P., \& Castillo, O. (2008). A new biometric recognition technique based on hand geometry and voice using neural networks and fuzzy logic. Soft Computing for Hybrid Intelligent Systems, 171-186.

Yam, J., \& Chow, T. (2000). A weight initialization method for improving training speed in feedforward neural network. Neurocomputing, 30(1-4), 219-232.

Yeung, D. S., Chan, P. P., \& Ng, W. W. (2009). Radial basis function network learning using localized generalization error bound. Information Sciences, 179(19), 31993217. 
